\title{
EFFECT OF INTRAVENOUS MAGNESIUM SULPHATE ON CARDIOVASCULAR RESPONSES DURING TRACHEAL EXTUBATION IN PATIENT UNDERGOING CRANIOTOMIES
}

\author{
Shikha Goyal1, Sourabh Shrivastava ${ }^{2}$
}

${ }^{1}$ Consultant, Department of Anaesthesia, Apollo Hospital, Gwalior.

2Private Practice, Department of Anaesthesia, Gwalior.

\section{ABSTRACT}

\section{BACKGROUND}

During emergence of general anaesthesia, hypertension and tachycardia caused by tracheal extubation may lead to serious complications during craniotomies. This study was designed to assess the effect of magnesium sulphate on these cardiovascular responses during extubation following craniotomies under general anaesthesia.

\section{MATERIALS AND METHODS}

Sixty patients of ASA Grade I and II, aged 18 - 50 yrs. undergoing craniotomies for nonvascular ICSOL were randomised into 2 groups with 30 patients in each group. Patients in Group M received an IV infusion of magnesium sulphate $30 \mathrm{mg} / \mathrm{kg}$ and Group C received $100 \mathrm{~mL}$ normal saline at the time of skin closure over 10 mins. Heart rate, systolic and diastolic blood pressure were recorded prior to drug infusion, 3 and 5 mins after drug infusion, during extubation and at 3, 5, 10 and 15 minutes after extubation. Side effects like bradycardia, hypotension, nausea, vomiting, shivering and desaturation also noted. Statistical analysis was performed by the use of Student's ' $t$ ' test and chi-square test.

\section{RESULTS}

As compared with baseline heart rate and blood pressure increase in both groups during and after extubation, heart rate was lower in Group M than Group C during extubation till 15 minutes after extubation $(\mathrm{p}<0.05)$. In Group M, systolic blood pressure was lower from 3 mins after study drug infusion to 10 mins after extubation and diastolic blood pressure was lower during extubation till 10 mins after extubation ( $<<0.05$ ). The groups did not differ significantly in regard to the prevalence of adverse effects.

\section{CONCLUSION}

We conclude that using of magnesium sulphate before extubation decreases the undesirable cardiovascular responses during extubation period.

\section{KEYWORDS}

Cardiovascular Response, Extubation, Magnesium Sulphate, Craniotomy.

HOW TO CITE THIS ARTICLE: Goyal S, Shrivastava S. Effect of intravenous magnesium sulphate on cardiovascular responses during tracheal extubation in patient undergoing craniotomies. J. Evolution Med. Dent. Sci. 2017;6(43):3367-3370, DOI: $10.14260 /$ Jemds/2017/729

\section{BACKGROUND}

Laryngoscopy and intubation causes significant changes in haemodynamics of patients, a similar set of derangement in haemodynamics have been noticed during extubation. ${ }^{1}$ Tracheal extubation is the discontinuation of an artificial airway when the indication for its placement like airway obstruction, protection of airway, suctioning, ventilatory failure and hypoxaemia no longer exists. These haemodynamic changes occur due to excessive catecholamine release which may result in tachycardia, hypertension and increased myocardial oxygen consumption. . $^{2,3}$

These complications may have serious consequences in patients undergoing craniotomies for ICSOL under general anaesthesia.

Financial or Other, Competing Interest: None.

Submission 22-04-2017, Peer Review 17-05-2017,

Acceptance 22-05-2017, Published 29-05-2017.

Corresponding Author:

Dr. Shikha Goyal,

18/43, Near Vachnalaya,

Shiksha Nagar,

Morena-476001.

E-mail: drshikhagoyal87@gmail.com

DOI: $10.14260 /$ jemds $/ 2017 / 729$
Intracranial haemorrhage can be a serious and sometimes fatal complication when it occurs during or after intracranial surgery. Sudden increase in arterial pressure may lead to increase in both cerebral blood flow and intracranial pressure, which may result in either herniation of brain contents or decrease in cerebral perfusion pressure leading to cerebral ischaemia. ${ }^{4}$ In literature a variety of drugs and techniques have been recommended for the control of these haemodynamic events including esmolol, ${ }^{5}$ fentanyl, ${ }^{6}$ diltiazem, ${ }^{7}$ verapamil ${ }^{7}$ and lignocaine. ${ }^{2}$

Parenteral magnesium sulphate has been used for many years as an antiarrhythmic agent and for prophylaxis against seizure in preeclampsia. ${ }^{8}$ Magnesium is the fourth most abundant cation in the body and the second most common intracellular cation after potassium. It is involved in several processes like control of vasomotor tone, cardiac excitability, neurotransmitter release and modulation of pain. Because of its numerous physiologic activities, magnesium is called "physiological calcium antagonist." ${ }^{9}$ Apart from that, magnesium blunts the haemodynamic response associated with endotracheal intubation. ${ }^{10}$

This study was planned to investigate the effect of magnesium sulphate in attenuation of cardiovascular responses during tracheal extubation in craniotomies for ICSOL under general anaesthesia and to study the side effects of the drug if any. 


\section{MATERIALS AND METHODS}

After obtaining Ethics Committee approval this prospective, randomised, double-blind clinical study was carried out on 60 patients after getting written informed consent from the patients.

\section{Inclusion Criteria}

- Patients of ASA Grade I and II.

- Patients of age group 18 to 50 years of either sex.

- Patients undergoing craniotomies for nonvascular ICSOL under GA.

\section{Exclusion Criteria}

- Patients with cardiopulmonary diseases.

- Patients on antihypertensive, antiarrhythmic, adrenoreceptor agonist and antagonist.

- Patients with renal dysfunction and hepatic dysfunction.

- Pregnant and lactating patients.

- Any patient who required postoperative ventilation.

- $\quad$ Patients with psychiatric illness.

Pre-anaesthetic assessments of all the selected patients were done with complete history and physical examination. Routine investigations like complete blood count, blood sugar, blood urea, serum creatinine, chest x-ray and ECG were done.

\section{Randomisation}

Based on a computer generated random number table using Microsoft Excel, all the patients were randomised into 2 groups (Group M and Group C) of 30 patients each.

All the patients were kept nil orally for 6 hours before procedure. All patients were uniformly pre-medicated with Inj. glycopyrrolate $0.2 \mathrm{mg}$ IM 30 mins before shifting to operation theatre.

Upon arrival of the patient in the operation theatre, intravenous access with $18-\mathrm{G}$ cannula was established. Crystalloid (Normal saline) infusion was started. Various monitoring devices like NIBP, pulse oximeter, 3 leads ECG were connected and basal heart rate (beats per minute), systolic and diastolic blood pressure (SBP and DBP) (mmHg), $\mathrm{SpO}_{2}(\%)$ were recorded.

Patients were medicated with Inj. pentazocine IV 0.5 $\mathrm{mg} / \mathrm{kg}$ followed by preoxygenation with $100 \%$ oxygen for 3 minutes. Induction of general anaesthesia was done with Inj. thiopentone sodium $5 \mathrm{mg} / \mathrm{kg}$ BW. Endotracheal intubation was facilitated with intravenous succinylcholine $1.5 \mathrm{mg} / \mathrm{kg}$ BW and ventilation with $100 \%$ oxygen for 1 minute.

General anaesthesia was maintained with nitrous oxide and oxygen (66:33) and isoflurane (0.5 - 1\%) given by Bain's circuit with intermittent dosage of non-depolarising muscle relaxant IV vecuronium loading dose- $0.04 \mathrm{mg} / \mathrm{kg}$ and intermittent dose- $0.01 \mathrm{mg} / \mathrm{kg}$ throughout surgical procedure.

At the time of skin closure, isoflurane was discontinued. In Group M $30 \mathrm{mg} / \mathrm{kg}$ inj. magnesium sulphate in $100 \mathrm{~mL}$ normal saline and in Group C normal saline $100 \mathrm{~mL}$ were given over a period of 10 minutes. Residual muscle paralysis was reversed with inj. neostigmine $(0.05 \mathrm{mg} / \mathrm{kg})$ and inj. glycopyrrolate $(0.01 \mathrm{mg} / \mathrm{kg}) \mathrm{IV}$. Once patient was conscious and responded to verbal command, extubation was performed and all patients were given $\mathrm{O}_{2}$ by face mask during recovery period. Values for heart rate, SBP and DBP were recorded just before the study drug administration $\left(A_{0}\right)$, which was taken as baseline value for comparison and 3, 5 mins after the study drug administration $\left(\mathrm{A}_{3}\right.$ and $\left.\mathrm{A}_{5}\right)$, at extubation (E) and at 3, 5, 10 and 15 mins after extubation $\left(\mathrm{E}_{3}, \mathrm{E}_{5}, \mathrm{E}_{10}, \mathrm{E}_{15}\right)$.

Patients were closely observed for bradycardia (below $20 \%$ of basal value), hypotension (below $20 \%$ of basal value) and desaturation $(<85 \%)$ during intra- and post-operative period. During postoperative period, along with the above nausea, vomiting and shivering were also recorded if occurred. Any complication if occurred was treated with appropriate medications.

With the power of study being $80 \%$ and confidence limits at $95 \%$, minimum sample size required to detect $30 \%$ reduction in haemodynamic parameters was 24 patients in each group. We conducted study with 30 patients in each group to make it more authentic. The observations recorded in all the groups were tabulated and statistical analysis carried out by using appropriate statistical software SPSS 17. To compare adverse effects, chi-square statistical test and to compare repeated haemodynamic parameters Student's ' $\mathrm{t}$ ' test was used. $\mathrm{P}$ value $<0.05$ was taken statistically significant and $\mathrm{p}$ value $<0.001$ was taken to be statistically highly significant.

\section{RESULTS}

The groups were well matched for age, male: female ratio, weight and duration of anaesthesia. The statistical difference was insignificant $(\mathrm{p}>0.05)$.

\begin{tabular}{|c|c|c|}
\hline Variables & Group C & Group M \\
\hline Age (yrs.) & $38.26 \pm 10.65$ & $34.7 \pm 9.01$ \\
\hline Sex (male: female) & $14: 16$ & $16: 14$ \\
\hline Weight (kg) & $60.63 \pm 9.74$ & $63.4 \pm 9.10$ \\
\hline Duration of Anaesthesia (min) & $176.66 \pm 38.10$ & $176.83 \pm 35.82$ \\
\hline \multicolumn{2}{|c|}{ Table 1. Demographic Profile of 2 Groups } \\
\hline
\end{tabular}

Baseline heart rate, SBP and DBP were comparable in both groups. Heart rate was significantly higher in Group $C$ than Group M during extubation till 15 mins after extubation $(\mathrm{p}<0.05)$.

SBP was significantly higher in Group C than Group M at 3 and 5 mins after study drug administration, during extubation and at 3, 5 and 10 mins after extubation $(p<0.05)$.

DBP was higher in Group $C$ during extubation and at 3, 5 and 10 mins after extubation $(\mathrm{p}<0.05)$.

Nausea and shivering were found in 1 and 2 patients respectively in Group C. No other side effects or complications were observed in both groups. The difference was statistically insignificant ( $p>0.05)$.

\begin{tabular}{|c|c|c|c|}
\hline \multicolumn{4}{|c|}{ Heart Rate } \\
\hline Time in min. & Group C & Group M & P-value \\
\hline $\mathrm{A}_{0}$ & $80.83 \pm 11.45$ & $77.60 \pm 9.49$ & .239 \\
\hline $\mathrm{A}_{3}$ & $81.63 \pm 10.98$ & $78.80 \pm 8.76$ & .274 \\
\hline $\mathrm{A}_{5}$ & $83.10 \pm 11.17$ & $80.93 \pm 8.68$ & .40 \\
\hline $\mathrm{E}$ & $104.03 \pm 17.65$ & $94.26 \pm 12.01$ & .015 \\
\hline $\mathrm{E}_{3}$ & $100.03 \pm 17.02$ & $89.83 \pm 12.80$ & .011 \\
\hline $\mathrm{E}_{5}$ & $96.63 \pm 16.08$ & $87.40 \pm 12.72$ & .017 \\
\hline $\mathrm{E}_{10}$ & $92.20 \pm 14.39$ & $84.86 \pm 12.55$ & .04 \\
\hline $\mathrm{E}_{15}$ & $90.50 \pm 11.24$ & $82.66 \pm 12.95$ & .015 \\
\hline
\end{tabular}

Table 2. Haemodynamic Parameters in the Study Groups 
Measurement points; $A_{0}$ : During study drug administration, $A_{3}: 3$ minutes after drug administration, $A_{5}: 5$ minutes after drug administration, $E$ : At the time of extubation, E3: 3 minutes after extubation, E5: 5 minutes after extubation, $\mathrm{E}_{10}: 10$ minutes after extubation, $\mathrm{E}_{15}: 15$ minutes after extubation. $\mathrm{M}=$ Magnesium Sulphate, $\mathrm{C}=$ Control.

\begin{tabular}{|c|c|c|c|c|c|c|}
\hline \multicolumn{9}{|c|}{ SBP } & \multicolumn{3}{c|}{ DBP } \\
\hline Time in min. & Group C & Group M & P-value & Group C & Group M & P-value \\
\hline $\mathrm{A}_{0}$ & $123.83 \pm 9.40$ & $123.96 \pm 11.08$ & .96 & $76.86 \pm 8.90$ & $78.70 \pm 9.99$ & .456 \\
\hline $\mathrm{A}_{3}$ & $124.86 \pm 9.53$ & $118.63 \pm 11.06$ & .023 & $77.96 \pm 8.37$ & $74.60 \pm 9.70$ & .156 \\
\hline $\mathrm{A}_{5}$ & $126.60 \pm 11.42$ & $119.70 \pm 11.35$ & .022 & $78.70 \pm 8.22$ & $76.10 \pm 10.93$ & .302 \\
\hline $\mathrm{E}$ & $145.93 \pm 8.25$ & $135.56 \pm 12.10$ & .000 & $95.73 \pm 9.36$ & $88.40 \pm 10.09$ & .005 \\
\hline $\mathrm{E}_{3}$ & $141.13 \pm 7.41$ & $132.43 \pm 11.47$ & .001 & $92.26 \pm 9.02$ & $85.50 \pm 10.47$ & .01 \\
\hline $\mathrm{E}_{5}$ & $136.73 \pm 6.95$ & $129.50 \pm 11.37$ & .004 & $89.63 \pm 7.71$ & $83.63 \pm 9.97$ & .012 \\
\hline $\mathrm{E}_{10}$ & $132.70 \pm 6.75$ & $127.10 \pm 11.02$ & .021 & $86.03 \pm 6.77$ & $80.36 \pm 9.75$ & .011 \\
\hline $\mathrm{E}_{15}$ & $128.96 \pm 8.05$ & $124.60 \pm 11.08$ & .086 & $82.50 \pm 6.80$ & $78.30 \pm 10.77$ & .07 \\
\hline \multicolumn{7}{|c|}{ Table 3. Haemodynamic Parameters in the Study Groups } \\
\hline
\end{tabular}

Measurement points; $A_{0}$ : During study drug administration, $A_{3}: 3$ minutes after drug administration, $A_{5}: 5$ minutes after drug administration, E: At the time of extubation, $E_{3}: 3$ minutes after extubation, $E_{5}: 5$ minutes after extubation, E10: 10 minutes after extubation, E15: 15 minutes after extubation. $\mathrm{M}=$ Magnesium Sulphate, $\mathrm{C}=$ Control, $\mathrm{SBP}=$ Systolic Blood Pressure, DBP $=$ Diastolic Blood Pressure

\section{DISCUSSION}

Tracheal extubation seems to be a benign procedure, but it can cause marked elevation in blood pressure and heart rate which may persist till the recovery period. Although precise mechanism responsible for these changes are not known, possible stimuli may be emerging from anaesthesia, tracheal irritation and wound pain. ${ }^{11}$ There is release of catecholamine occurring during this stressful period. These haemodynamic changes has a major concern for patients with coronary artery disease, ${ }^{3}$ cerebrovascular disease ${ }^{12}$ and in hypertensive patients. ${ }^{13}$

Magnesium inhibits the release of catecholamine from both adrenal glands and adrenergic nerve terminals in response to sympathetic stimulation. ${ }^{14}$ It is also capable of attenuating vasopressin stimulated vasoconstriction. ${ }^{15}$ Intravenously administered magnesium sulphate is capable of attenuating the adverse haemodynamic response associated with endotracheal intubation. ${ }^{10}$

In this study, we used magnesium sulphate before extubation to find out the attenuating effect on cardiovascular system response during tracheal extubation following craniotomies. We found in our study that heart rate was increased at 5 mins after magnesium sulphate infusion. This was probably due to the fact that $\mathrm{Mg}^{++}$inhibits the release of acetylcholine from the vagus nerve, so it produces tachycardia initially. Heart rate was higher in control group as compared to magnesium sulphate group during and after extubation. This was probably due to the fact that epinephrine levels in the magnesium sulphate group did not increase as significant, whereas in the control group there was a significant increase in epinephrine level.

Arar C et al ${ }^{16}$ support our study, they also used magnesium sulphate during extubation and found that heart rate was significantly lower in magnesium sulphate group as compared to control group. Montazeri K and Fallah $\mathrm{M}^{17}$ compared 5 doses of magnesium sulphate (50, 40, 30, 20 and $10 \mathrm{mg} / \mathrm{kg} \mathrm{IV}$ ) and IV lignocaine $1.5 \mathrm{mg} / \mathrm{kg}$ for attenuation of haemodynamic response to endotracheal intubation. They concluded that $30 \mathrm{mg} / \mathrm{kg}$ dose is optimum dose for haemodynamic stability with less unexpected effects during intubation period.

Above mentioned studies supported the use of safe dose of IV magnesium sulphate $(30 \mathrm{mg} / \mathrm{kg}$ ), which was similar to our study with no incidence of adverse effects. James MFM et $\mathrm{al}^{18}$ Kiaee MM et $\mathrm{al}^{19}$ and Piplai G et $\mathrm{al}^{20}$ also used IV magnesium sulphate for stabilisation of heart rate during intubation and found similar result.

$\mathrm{Mg}^{++}$directly acts on blood vessels and also indirectly by sympathetic ganglia blockade, so it leads to decrease in arterial blood pressure.10 It reduces responsiveness of vascular smooth muscle to norepinephrine stimulation. It competes with calcium for membrane channels. From our study, it was observed that SBP was lower in Group M compared to control group at all time from 3 mins of study drug infusion to 10 mins after extubation, whereas DBP was lower during extubation till 10 mins after extubation.

In a study on hypertensive patients by Panda NB et al,21 magnesium sulphate infusion at a dose of 30, 40 and 50 $\mathrm{mg} / \mathrm{kg}$ were given at induction of anaesthesia. Blood pressure was maintained within normal limit with $30 \mathrm{mg} / \mathrm{kg}$ magnesium sulphate and intervention required for hypotension in patients receiving 40 and $50 \mathrm{mg} / \mathrm{kg}$ of magnesium sulphate. They concluded that $30 \mathrm{mg} / \mathrm{kg}$ magnesium sulphate was better for stabilisation for haemodynamics during intubation.

Our results are in accordance with Arar $\mathrm{C}$ et al, ${ }^{16}$ Nooraei $\mathrm{N}$ et $\mathrm{al}^{22}$ and Puri GD et al. ${ }^{10}$

Shivering (6.66\%) and nausea (3.33\%) were observed only in control group patients. Beside these, no untoward side effects occurred in any group. The difference was statistically insignificant between groups $(\mathrm{p}>0.05)$.

Piplai $\mathrm{G}^{20}$ also had done a study with magnesium sulphate and found similar results.

\section{CONCLUSION}

Magnesium sulphate administration before the extubation significantly decreases the cardiovascular response to tracheal extubation. 


\section{REFERENCES}

[1] Jain D, Khan R, Maroof M. Effect of dexmedetomidine on stress response to extubation. Internet $\mathrm{J}$ Anesthesiol 2008;21(1):1-3.

[2] Sharma VB, Prabhakar H, Rath GP, et al. Comparison of dexmedetomidine and lignocaine on attenuation of airway and pressor responses during tracheal extubation. J Neuroanaesthesiol Crit Care 2014;1(1):50-5.

[3] Paulissian R, Salem MR, Joseph NJ, et al. Hemodynamic responses to endotracheal extubation after coronary artery bypass grafting. Anesth Analg 1991;73(1):10-5.

[4] Goarya RS, Mathur A. I/V bolus dexmedetomidine attenuates the airway reflexes and hemodynamic responses during extubation following general anaesthesia. Journal of Evolution of Medical and Dental Sciences 2014;3(65):14114-28.

[5] Alkaya MA, Saraçoğlu KT, Pehlivan G, et al. Effects of esmolol on the prevention of haemodynamic responses to tracheal extubation after craniotomy operations. Turk J Anaesth Reanim 2014;42(2):86-90.

[6] Aksu R, Akın A, Biçer C, et al. Comparison of the effects of dexmedetomidine versus fentanyl on airway reflexes and hemodynamic responses to tracheal extubation during rhinoplasty: a double-blind, randomized, controlled study. Curr Ther Res Clin Exp 2009;70(3):209-20.

[7] Mikawa K, Nishina K, Maekawa N, et al. Attenuation of cardiovascular responses to tracheal extubation: Verapamil v/s Diltiazem. Anaesthesia \& Analgesia 1996;82(6):1205-10.

[8] James MF. Clinical use of magnesium infusions in anaesthesia. Anaesthesia \& Analgesia 1992;74(1): 129-36.

[9] Fawcett WJ, Haxby EJ, Male DA. Magnesium: physiology and pharmacology. $\mathrm{Br} \mathrm{J}$ Anaesth 1999;83(2):302-20.

[10] Puri GD, Marudhachalam KS, Chari P, et al. The effect of magnesium sulphate on hemodynamics and its efficacy in attenuating the response to endotracheal intubation in patients with coronary artery disease. Anesth Analg 1998;87(4):808-11.

[11] Guler G, Akin A, Tosun Z, et al. Single-dose dexmedetomidine attenuates airway and circulatory reflexes during extubation. Acta Anesthesiol Scand 2005;49(8):1088-91.

[12] Parida S, Badhe A. Emergence hypertension in patients undergoing intracranial surgery. The Internet J Anesthesiol 2008;22(1):1-5.
[13] Dogru K, Arik T, Yildiz K, et al. The effectiveness of intramuscular dexmedetomidine on haemodynamic responses during tracheal intubation and anaesthesia induction of hypertensive patients: a randomised, double blind, placebo controlled study. Curr Ther Res Clin Exp 2007;68(5):292-302.

[14] Douglas WW, Rubin RP. The mechanism of catecholamine release from the adrenal medulla and the role of calcium in stimulus-secretion coupling. The Journal of Physiology 1963;167(2):288-310.

[15] Laurant P, Touyz RM, Schiffrin EL. Effect of magnesium on vascular tone and reactivity in pressurized mesenteric resistance arteries from spontaneously hypertensive rats. Canadian Journal of Physiology and Pharmacology 1997;75(4):293-300.

[16] Arar C, Colak A, Alagol A, et al. The use of esmolol and magnesium to prevent haemodynamic responses to extubation after coronary artery grafting. Eur J Anaesthesiol 2007;24(10):826-31.

[17] Montazeri K, Fallah M. A dose-response study of magnesium sulfate in suppressing cardiovascular responses to laryngoscopy \& endotracheal intubation. Journal of Research in Medical Sciences 2005;10(2):82-6.

[18] James MFM, Beer RE, Esser JD. Intravenous magnesium sulfate inhibits catecholamine release associated with tracheal intubation. Anaesthesia \& Analgesia 1989;68(6):772-6.

[19] Kiaee MM, Safari S, Movaseghi GR, et al. The effect of intravenous magnesium sulfate and lidocaine in hemodynamic responses to endotracheal intubation in elective coronary artery bypass grafting: a randomized controlled clinical trial. Anaesthesiology and Pain Medicine 2014;4(3):e15905.

[20] Piplai G, Mukhopadhyay M, Maji A, et al. Effects of magnesium sulphate on haemodynamic response to endotracheal intubation, anaesthetic requirement and postoperative opioid consumption in patients undergoing spine surgery. International Journal of Pharmacology \& Therapeutics 2013;3(3):73-84.

[21] Panda NB, Bharti N, Prasad S. Minimal effective dose of magnesium sulfate for attenuation of intubation response in hypertensive patients. Journal of Clinical Anaesthesia 2013;25(2):92-7.

[22] Nooraei N, Dehkordi ME, Radpay B, et al. Effects of intravenous magnesium sulfate and lidocaine on hemodynamic variables following direct laryngoscopy and intubation in elective surgery patients. Tanaffos 2013;12(1):57-63. 